\title{
Caffeine and Ciprofloxacin Adsorption from Water onto Clinoptilolite: Linear Isotherms, Kinetics, Thermodynamic and Mechanistic Studies
}

\author{
Emily C. Ngeno ${ }^{a}$, Victor O. Shikuku ${ }^{\mathrm{a}, \mathrm{b}, *(\mathbb{D}) \S}$, Francis Orata ${ }^{\mathrm{a}}$, Lilechi D. Baraza and Selly J. Kimosop ${ }^{\mathrm{a}}$ \\ ${ }^{a}$ Masinde Muliro University of Science and Technology, P.O.Box 190 Kakamega, Kenya. \\ ${ }^{b}$ Kaimosi Friends University College, P.O. Box 385-50309, Kaimosi, Kenya.
}

Received 11 June 2018, revised 14 May 2019, accepted 14 June 2019.

\begin{abstract}
In this study, clinoptilolite was used to sequester ciprofloxacin (CIP) and caffeine (CAF), two emergent contaminants, from aqueous solution using batch equilibration method and the effects of contact time, $\mathrm{pH}$, initial contaminant concentration, temperature and adsorbent dosage investigated and herein reported. The adsorption kinetics was described by the pseudo-second-order model (PSO) and pore diffusion was not the sole operative rate-controlling step as depicted by the intraparticle diffusion model. The equilibrium data were modelled using three linear forms of Langmuir equation and Freundlich model and was best fitted by the Lineweaver-Burk linearization of Langmuir equation (type-1). Linearization is shown to induce errors that may lead to discrepancies in parameter values estimation. The derived thermodynamic functions revealed the adsorption processes are exothermic, spontaneous and physical in nature. The adsorption mechanism of CIP is strongly controlled by electrostatic interactions while CAF adsorption is weakly affected by changes in $\mathrm{pH}$. The findings demonstrate that clinoptilolite in its unmodified form is a potential low-cost and eco-friendly adsorbent for removal of pharmaceutically active ingredients from water.
\end{abstract}

KEYWORDS

Caffeine, ciprofloxacin, adsorption, clinoptilolite, linear isotherms.

\section{Introduction}

Pharmaceutical compounds (PhCs) are compounds manufactured for use in health care as medicinal drugs to prevent, mitigate or cure diseases in humans as well as animals. Due to their widespread and increasing usage, PhCs have been frequently detected in surface waters, treated wastewaters and in portable water. ${ }^{1,23}$ Their occurrence in water and subsequent interaction with non-target organisms causes chronic toxicity, endocrine disruption and induce development of resistant bacteria strains among other problems, raising serious environmental and health concerns. ${ }^{4}$ Traditional wastewater treatment plants (WWTPs) are therefore not tailored to completely abstract these contaminants. As such, alternative low-price, environmentally friendly and sustainable wastewater treatment approaches for removal of the so called 'emerging contaminants' is a subject of ongoing research.$^{5,6}$ Adsorption process still remains the widely used technique for water treatment since it is environmentally friendly, cheap and relatively simple and various adsorbents for removal of PCs such as clays, biochars, zeolites have been reported in literature. ${ }^{7}$ Zeolites are facile materials in abatement of pollutants from water due to their generally high adsorption densities, catalytic properties and their inherent potential to be regenerated with minimum loss of their original properties. ${ }^{8,9}$ However, synthetic zeolites are costly relative to their naturally occurring counterparts. The aim of this study was to evaluate the adsorption characteristics of naturally occurring zeolitic tuff of Kenyan origin (NZ-K) for caffeine (CAF) and ciprofloxacin (CIP) (Fig. 1, Table 1) removal from water under varied environmental parameters.

* To whom correspondence should be addressed. E-mail: vshikuku@ kafuco.ac.ke

\section{Materials and Methods}

\subsection{Preparation of Adsorbent}

The zeolite material was crushed, homogenized and applied for adsorption without chemical modification. The homogenized sample was passed through 212-300 $\mu \mathrm{m}$ sieves for controlled uniform particle size. The sieved material was then triple washed in ultrapure water and then dried in an oven at a temperature of $80^{\circ} \mathrm{C}$ for 2 hours. The zeolite was identified by XRD analysis as clinoptilolite. The XRD instrument settings were $40 \mathrm{KV}, 30 \mathrm{~mA}$, step size of $0.02^{\circ}(2 \theta$-LC) and a scan rate of $2 \theta$-LC $\min ^{-1}$ for $5^{\circ} \leq(2 \theta$-LC $) \leq 50^{\circ}$. The chemical composition was $\mathrm{SiO}_{2} 62.2 \%, \mathrm{Al}_{2} \mathrm{O}_{3} 13.3 \%, \mathrm{CaO} 12.0 \%, \mathrm{MgO} 1.64 \%, \mathrm{Na}_{2} \mathrm{O}$ $3.09 \%, \mathrm{~K}_{2} \mathrm{O} 0.17 \%$, $\mathrm{MnO} 0.2 \%$ and $\mathrm{Fe}_{2} \mathrm{O}_{3} 4.83 \%$. ${ }^{8}$ The $\mathrm{pH}$ at point of zero surface charge $\left(\mathrm{pH}_{\mathrm{pzc}}\right)$ was obtained using the protocol reported in literature. ${ }^{11}$

\subsection{Adsorption Experiments}

Here, triplicate samples of $0.1 \mathrm{~g}$ of the adsorbent were mixed with $50 \mathrm{~mL}$ of $5 \mathrm{mg} \mathrm{L}^{-1}$ of each adsorbate singly in batch mode and the contents shaken at $120 \mathrm{rpm}$ until equilibrium was attained. At predetermined regular time intervals an aliquot of supernatant was extracted for determination of residual CAF or $\mathrm{CIP}$. The effect of $\mathrm{pH}$ on adsorption of the compounds was investigated for a concentration of $5 \mathrm{mg} \mathrm{L}^{-1}$ and $0.1 \mathrm{~g} 50 \mathrm{~mL}^{-1}$ adsorbent dosage for $\mathrm{pH}$ in the range 2.0-12. The solution $\mathrm{pH}$ was modified usng $0.1 \mathrm{M} \mathrm{NaOH}$ and $0.1 \mathrm{M} \mathrm{H}_{2} \mathrm{SO}_{4}$. Adsorption isotherm studies were carried out at different initial adsorbate concentrations $\left(2-10 \mathrm{mg} \mathrm{L}^{-1}\right)$ at $25^{\circ} \mathrm{C}$. The effect of zeolite dosage on adsorption efficiency was obtained by mixing $50 \mathrm{~mL}$ of $5 \mathrm{mg} \mathrm{L}^{-1}$ of each 


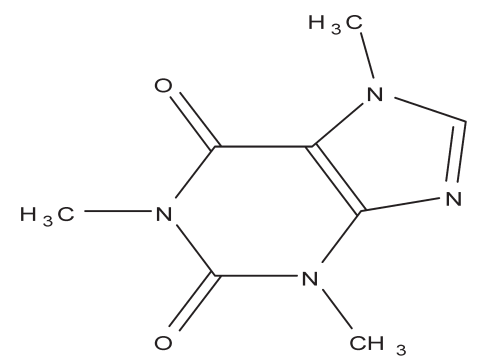

(a)<smiles>O=C(O)c1cn(C2CC2)c2cc(N3CCNCC3)c(F)cc2c1=O</smiles>

(b)

Figure 1 Structures of caffeine (a) and ciprofloxacin (b).

Table 1 The physico-chemical parameters of CIP and CAF.

\begin{tabular}{lll}
\hline $\begin{array}{l}\text { Physico-chemical } \\
\text { parameters }\end{array}$ & \multicolumn{1}{c}{ CAF } & \multicolumn{1}{c}{ CIP } \\
\hline Molecular weight & $194.19 \mathrm{~g} \mathrm{~mol}^{-1}$ & $331.34 \mathrm{~g} \mathrm{~mol}^{-1}$ \\
Molecular formulae & $\mathrm{C}_{8} \mathrm{H}_{10} \mathrm{~N}_{4} \mathrm{O}_{2}$ & $\mathrm{C}_{17} \mathrm{H}_{18} \mathrm{FN}_{3} \mathrm{O}_{3}$ \\
$\mathrm{pK}_{\mathrm{a}}$ & $14\left(25^{\circ} \mathrm{C}\right)$ & $6.1-8.7$ \\
Log Kow & -0.07 & 0.28 \\
Water solubilty & $21600\left(\mathrm{mg} \mathrm{L}^{-1}\right)$ & $150\left(\mathrm{mg} \mathrm{L}^{-1}\right)$ \\
\hline
\end{tabular}

(Adopted from Li et al. ${ }^{10}$ and Sotelo et al. ${ }^{3}$ )

compound with different amounts $(0.2,0.4,0.6,0.8,1.0$ and $1.2 \mathrm{~g}$ ) of the adsorbent (NZ-K) at $25^{\circ} \mathrm{C}$ until equilibration. The thermodynamic characteristics of the adsorption processes were studied in the temperature range $25-65^{\circ} \mathrm{C}$. Here, $0.1 \mathrm{~g}$ of NZ-K was added into $50 \mathrm{~mL}$ of $5 \mathrm{mg} \mathrm{L}^{-1}$ of each adsorbate and the contents shaken at $120 \mathrm{rpm}$ at different temperatures $(25,35$, 45,55 and $65{ }^{\circ} \mathrm{C}$ ) until equilibration. All experiments were performed in triplicates. After equilibration, residual amounts of each compound in solution were determined by UV-VIS spectrophotometer (Shimadzu-1800 model) at $273 \mathrm{~nm}$ and $274.8 \mathrm{~nm}$ for CAF and CIP, respectively. The amounts adsorbed from the bulk solution per unit mass $\left(\mathrm{mg} \mathrm{g}^{-1}\right)$ at a given time $(\mathrm{t})$ was calculated as:

$$
q_{t}=\frac{\left(C_{o}-C_{e}\right) V}{M}
$$

where $C_{\mathrm{o}}$ is the initial concentration $\left(\mathrm{mg} \mathrm{L}^{-1}\right), C_{e}$ is the equilibrium concentration $\left(\mathrm{mg} \mathrm{L}^{-1}\right), M$ is the mass of the adsorbent $(\mathrm{g})$ and $V$ is the volume of the solution (L). After equilibration, the residual adsorbate in solution was analyzed and the equilibrium adsorption capacity, $q_{e}$ was computed by the relation:

$$
q_{e}=\frac{\left(C_{o}-C_{e}\right) V}{M}
$$

\section{Results and Discussion}

\subsection{Adsorption Kinetics}

The adsorption of both CAF and CIP onto NZ-K exhibited fast kinetics with removal of $72.7 \% \mathrm{CAF}$ and $56.2 \% \mathrm{CIP}$ within the first $5 \mathrm{~min}$ (Fig. 2). This is due to the presence of large number of vacant binding sites at the onset. Maximum adsorption was achieved within $25 \mathrm{~min}$ for both compounds corresponding to $76.8 \%$ CAF and $61.8 \%$ CIP adsorption. This was followed by a near plateau phase with no appreciable changes in amounts adsorbed corresponding to equilibrium. The plateau phase is due to the difficulty of CAF and CIP molecules to access inner active zeolitic sites due to occupancy and repulsion between the molecules on the solid phase and those in the liquid phase. ${ }^{12}$ Short equilibrium times correspond to short preferable residence times in water treatment systems.

The time-dependence data were fitted to pseudo-first-order, ${ }^{13}$ pseudo-second-order, ${ }^{14}$ and intraparticle diffusion ${ }^{15}$ models to determine the reaction rates and nature of the rate-controlling step, respectively.

Pseudo-first-order model: $\log \left(q_{e}-q_{t}\right)=\log q_{e}-\frac{k_{1} t}{2.303}$

Pseudo-second-order model: $\frac{t}{q_{t}}=\frac{1}{k_{2}\left(q_{e}\right)^{2}}+\frac{t}{q_{e}}$

Intra-particle model: $q_{t}=k_{p} t^{0.5}+C$

The pseudo-first-order (PFO) model revealed extremely poor fitting to the data and the results are not herein discussed. The poor fitting is attributed to the difficulty in determination of the appropriate value of $q_{e}$ and the pseudo-equilibrium values selected. The variances between $q_{e}$ and $q_{t}$ resulted in mathematical errors resulting from taking logarithmic values of negative numbers hence PFO model was incapable of describing the kinetic data. Such difficulties have been reported by other



Figure 2 Variation of CAF and CIP amount adsorbed onto NZ-K with contact time (triplicate). 
researchers. ${ }^{16}$ The high coefficients of determination $\left(R^{2}\right)$ coupled with the close agreement between the experimental $\left(q_{\text {e(exp }}\right)$ and theoretical adsorption $\left(q_{e(t h e o r e t i c a l)}\right)$ capacities suggest that the adsorption of CAF and CIP onto the natural zeolite obey pseudo-second-order kinetics law (Table 2). The pseudosecond-order (PSO) model assumes a chemisorption-controlled rate-determining step and two adsorbate molecules are adsorbed in one binding site. However, due to the aforementioned difficulties related to the linear PFO model, this conclusion must be treated with care. The pseudo-second-order plots are depicted in Fig. 3.

The initial sorption rate $\left(S_{\text {rate }}\right)$ and the adsorption half-life $\left(t_{1 / 2}\right)$ were obtained from equations 6 and 7, respectively, where $k_{2}$ is the pseudo-second-order rate constant and $q_{e}$ is the equilibrium adsorption capacity.

$$
\begin{aligned}
& S_{\text {rate }}=k_{2} q_{e}^{2} \\
& t_{1 / 2}=\frac{1}{k_{2} q_{e}}
\end{aligned}
$$

Notably, CAF exhibited faster adsorption rate and short half-life despite its high solubility relative to CIP (Table 2). The higher time-scaling factor $k_{2}$ value for CAF implies the system has tendency to reach equilibrium faster than CIP system. Noteworthy, the half-lives are generally too short and would result in considerably short residence time in a real water treatment system.

The kinetic data was further modelled using intraparticle
Table 2 Pseudo-second-order kinetic parameters for CAF and CIP adsorption onto NZ-K (triplicate).

\begin{tabular}{lcccccc}
\hline PhC & $\mathrm{R}^{2}$ & $\begin{array}{c}\text { Initial rate } \\
/ \mathrm{mg} \mathrm{g}^{-1} \mathrm{~min}^{-1}\end{array}$ & $\begin{array}{c}\mathrm{t}_{1 / 2} \\
/ \mathrm{min}^{2}\end{array}$ & $\mathrm{k}_{2}$ & $\mathrm{q}_{\mathrm{e}(\text { theor) }}$ & $\mathrm{q}_{\text {e(exp) }}$ \\
\hline CAF & 0.999 & 2.849 & 0.610 & 0.945 & 1.736 & 1.789 \\
CIP & 0.998 & 1.848 & 0.828 & 0.789 & 1.531 & 1.605 \\
\hline
\end{tabular}

diffusion model (Eq. 5) to elucidate the rate-controlling step. According to the model, $t, q_{t}, k_{p}$ and $C$ is time, amount adsorbed at any given time, intraparticle diffusion rate constant and $C$ is a constant related to the mass transfer across the boundary layer, respectively. Accordingly, when the plot passes through the origin, the intraparticle diffusion is the sole operative rate-determining step. Otherwise, for non-zero intercept, other multiple processes, film diffusion, intra-particle diffusion or both, are involved in the rate-controlling step.

In the present work, the intraparticle diffusion plots yielded multi-linear plots that are bi-phased in nature, labelled I and II. During phase I, there is a steady increase attributed to the instantaneous fast initial adsorption attributed to external surface adsorption. Phase II depicts decrease in quantity adsorbed due to adsorption-desorption dynamics as the systems tends towards equilibration..$^{17}$ Evidently, the plots deviated from the origin (Fig. 4) implying that pore diffusion is not the only ratecontrolling step.

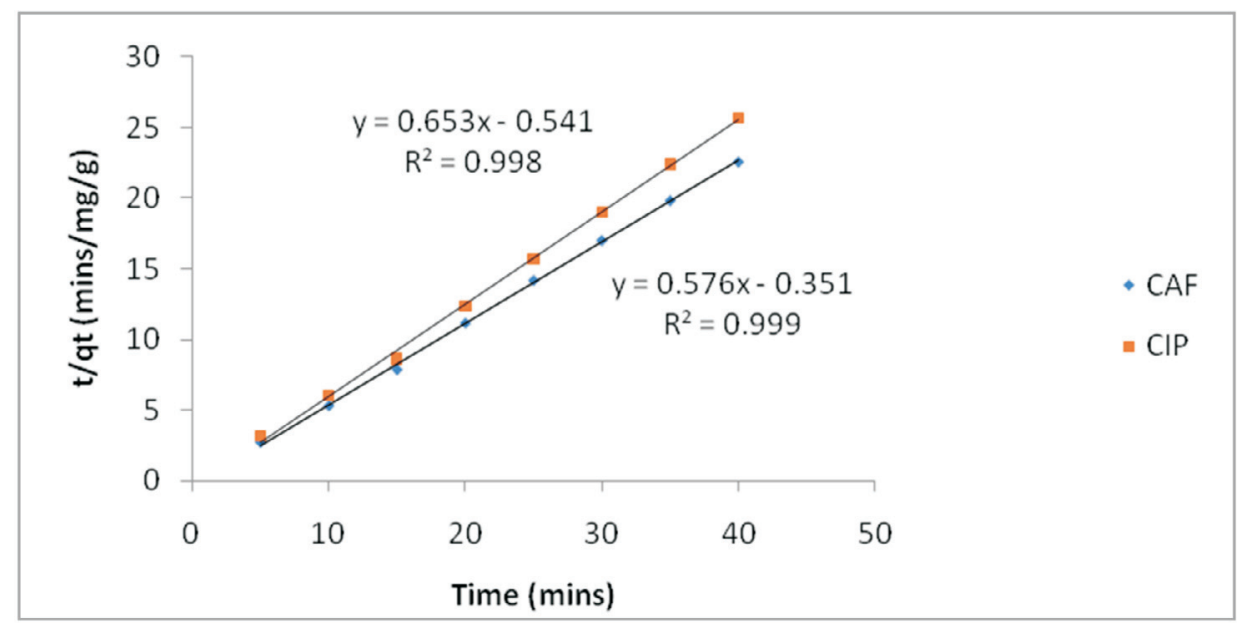

Figure 3 Pseudo-second-order kinetic model for CAF and CIP adsorption onto NZ-K (triplicate).

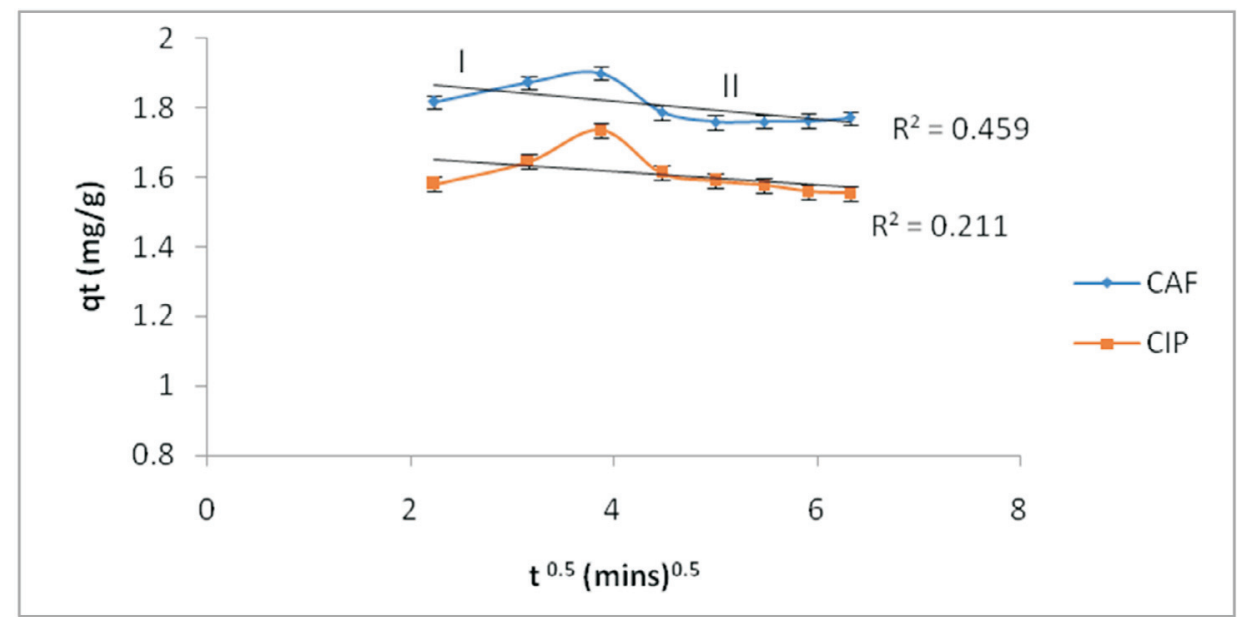

Figure 4 Intraparticle diffusion model for CAF and CIP adsorption onto NZ-K (triplicate). 


\subsection{Adsorption Thermodynamics}

The effect of temperature was studied in between 298-338 K holding other environmental conditions constant. The thermodynamic functions, changes in Gibb's free energy $(\Delta G)$, enthalpy $(\Delta \mathrm{H})$ and entropy $(\Delta \mathrm{S})$, related to the adsorption processes were computed using the relations below and results are summarized in Table 3:

$$
\begin{aligned}
& \Delta G=-\mathrm{RT} \ln K_{c} \\
& K_{c}=\frac{C_{a d s}}{C_{e}} \\
& \ln K_{c}=\frac{\Delta S}{R}-\frac{\Delta H}{R} \frac{1}{T}
\end{aligned}
$$

where $K_{c}$ is the equilibrium constant, $C_{e}$ is the equilibrium concentration in the solution $\left(\mathrm{mg} \mathrm{L}^{-1}\right)$ and $C_{a d s}$ is the equilibrium solid phase concentration $\left(\mathrm{mg} \mathrm{g}^{-1}\right) . R$ is the gas constant $\left(8.314 \mathrm{~J} \mathrm{~mol}^{-1} \mathrm{~K}^{-1}\right.$ ) and $T$ is the temperature in Kelvin.

From Table 3, the percentage (\%) removal for both compounds depreciated with rise in temperature indicating an exothermic process in which maximum adsorption was realized at room temperature. CIP adsorption was adversely retarded by rise in temperature relative CAF. This could be attributed to increased solubility at higher temperatures and therefore weakening the adsorbate affinity for the adsorbent surface. ${ }^{12}$

The negative $\Delta G$ values for CAF attest that adsorption of CAF onto NZ-K is favourable and spontaneous at the examined temperatures. However, the reaction becomes less favourable with increased temperature due to it being exothermic. On the other hand, CIP adsorption onto NZ-K was only favourable and spontaneous at $298 \mathrm{~K}$ but as temperature was raised beyond $298 \mathrm{~K}$, the adsorption reaction became thermodynamically nonspontaneous portraying that the exothermic CIP adsorption process exceeds the effect of increased mobility of the adsorbate molecules with rise in temperature. The results also shows that room temperatures are preferred which suits application in real wastewater treatment systems.

In literature, the magnitude of the $\Delta \mathrm{H}$ value is reported lie between 40 and120 $\mathrm{kJ} \mathrm{mol}^{-1}$ for chemisorption mechanism. ${ }^{8}$ In the present study, the $\Delta \mathrm{H}$ values $\left(2.728 \mathrm{~kJ} \mathrm{~mol}^{-1}\right.$ and $29.955 \mathrm{~kJ} \mathrm{~mol}^{-1}$ for CAF and CIP, respectively) imply the adsorption mechanism of CAF and CIP onto NZ-K is predominantly physical in nature which puts to doubt the chemisorption mechanisms alluded to by the PSO model. The negative $\Delta H$ values confirm that the adsorption processes are exothermic while the negative entropy values indicate increased orderliness at the solute/adsorbent interface.
Table 3 Thermodynamic parameters for CAF and CIP adsorption onto NZ-K (triplicate).

\begin{tabular}{lccccc}
\hline Compound & $\begin{array}{c}\text { Temp. } \\
/ \mathrm{K}\end{array}$ & \% Removal & $\begin{array}{c}\Delta \mathrm{G} \\
/ \mathrm{KJ} / \mathrm{mol})\end{array}$ & $\begin{array}{c}\Delta \mathrm{H} \\
/ \mathrm{kJ} \mathrm{mol}^{-1}\end{array}$ & $\begin{array}{c}\Delta \mathrm{S} \\
/ \mathrm{kJ} \mathrm{mol}^{-1}\end{array}$ \\
\hline CAF & 298 & 63.770 & -1.401 & -2.728 & -4.431 \\
& 308 & 62.782 & -1.339 & & \\
& 318 & 62.707 & -1.374 & & \\
& 328 & 61.337 & -1.258 & & \\
$\mathrm{CIP}$ & 338 & 60.651 & -1.216 & & \\
& 298 & 60.308 & -1.036 & -29.955 & -97.357 \\
& 308 & 48.516 & 1.521 & & \\
& 318 & 40.429 & 1.025 & & \\
& 328 & 31.129 & 2.165 & & \\
\hline
\end{tabular}

\subsection{Effect of $\mathrm{pH}$}

The effect of $\mathrm{pH}$ on adsorption of CAF and CIP onto NZ-K was studied in the range pH2.0-12.0 and the trend is shown in Fig. 5.

$\mathrm{CIP}$ was more pronouncedly affected by variation in $\mathrm{pH}$ with highest adsorption (99\%) achieved at $\mathrm{pH}$ 6. On the contrary, CAF adsorption was remotely affected by $\mathrm{pH}$ with a slightly highest adsorption $(72.4 \%)$ obtained at $\mathrm{pH}$ 8. Further increase in $\mathrm{pH}$ causes decrease in the adsorption percentage especially for CIP. These dynamics were explained by comparing the $\mathrm{pH}_{\mathrm{pzc}}$ of the adsorbent (Fig. 6) and the $\mathrm{pK}_{\mathrm{a}}$ values of the adsorbates.

Figure 6 revealed that the $\mathrm{pH}_{\mathrm{pzc}}$ of NZ-K was about 7.5. Consequently, at $\mathrm{pH}$ values below 7.5, the adsorption surface is expected to bear a net positive charge and was negatively charged at $\mathrm{pH}$ values $>7.5$. The $\mathrm{pK}_{\mathrm{a}}$ values of CIP are between 6.1 (attributed to carboxylic acid group) and 8.7 (assigned to the amine group on the piperazine) (Table 2 ). It can exist as a cation $\left(\mathrm{CIP}^{+}\right)$, a neutral ion $\left(\mathrm{CIP}^{0}\right)$ or an anion $\left(\mathrm{CIP}^{-}\right)$under different $\mathrm{pH}$ conditions. Therefore, $\mathrm{CIP}^{+}$is mostly cationic at $\mathrm{pH}<6.1$, the neutral form $\left(\mathrm{CIP}^{0}\right)$ dominates at $\mathrm{pH}$ 6.1-8.7, and occurs mainly in anionic $\mathrm{CIP}^{-}$species at $\mathrm{pH}>8.7 .{ }^{10}$ As a result, at $\mathrm{pH}$ below 6.1 both the protonated CIP molecules $\left(\mathrm{CIP}^{+}\right)$and the adsorbent surface were positively charged and the adsorption capacity is significantly reduced due to coulombic repulsion (Fig. 5). A similar trend is observed at $\mathrm{pH}$ above 8.7 where NZK surface predicted to be the negatively charged repels the $\mathrm{CIP}^{-}$anionic molecules. Therefore, the adsorption of CIP is largely controlled by electrostatic interactions. Furthermore, the high CIP adsorption observed at $\mathrm{pH} 6$ where the adsorbent is considered to be positively charged and the adsorbate molecules are largely

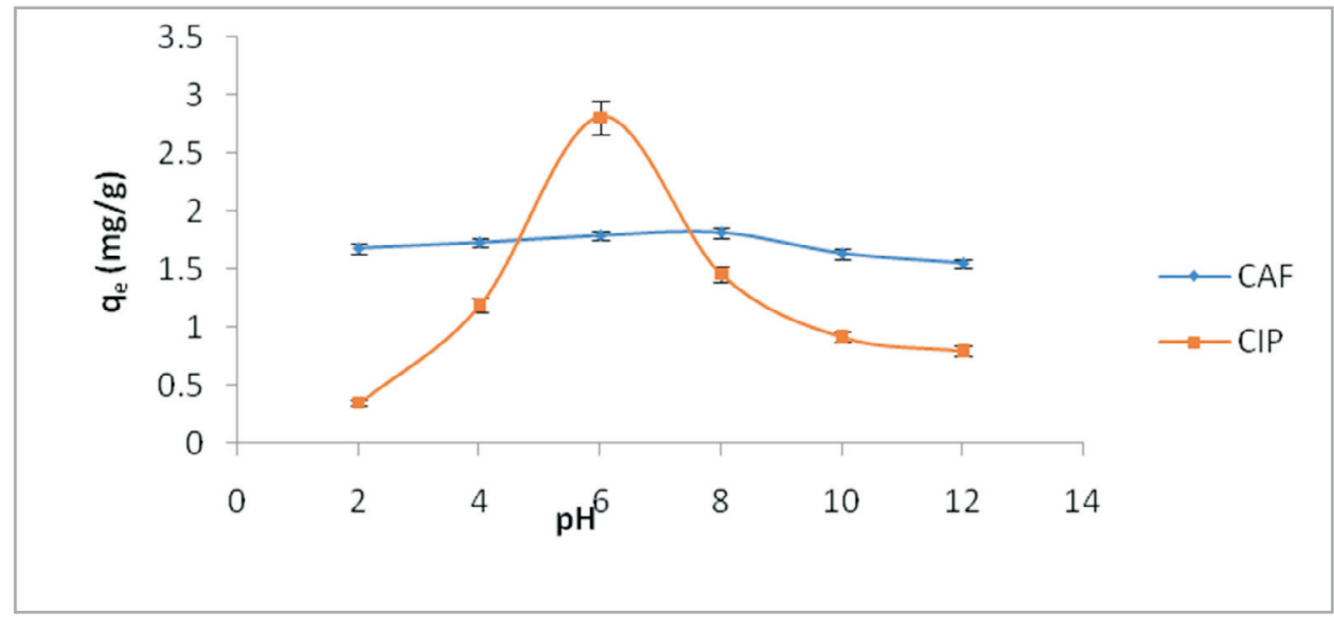

Figure 5 Variation of amount of CAF and CIP adsorbed onto NZ-K as a function of $\mathrm{pH}$ (triplicate). 
neutral indicate a non-electrostatic interactions account for CIP adsorption. Contrastingly, CAF adsorption is sparingly dependent on $\mathrm{pH}$ variance. $\mathrm{CAF}$ has a $\mathrm{pK}_{\mathrm{a}}$ of 14 below which the molecule exists in cationic form $\left(\mathrm{CAF}^{+}\right)$. Likewise, below the $\mathrm{pH}_{\mathrm{pzc}}$ the adsorption is decreased due to repulsion of $\mathrm{CAF}^{+}$and the positively charged adsorbent surface (Fig. 5). However, a notable increase is realized at $\mathrm{pH} 8$ when the adsorbent surface is positive bespeaking of a non-electrostatic interactions.

\subsection{Effect of Adsorbent Dosage}

Determination of the adsorbent dosage required for a given concentration of pollutant is a critical parameter for application in effluent treatment. The variation of adsorption capacity with rise in adsorbent dosage is shown in Fig. 7.

The amount of CAF and CIP adsorbed increased with increment of adsorbent dosage due to increase in the number of adsorption sites. Beyond $20 \mathrm{~g} \mathrm{~L}^{-1}$, there was minimal change in adsorption capacity as a result of overlapping of the adsorption sites with increased number of adsorbing particles.

\subsection{Adsorption Isotherm Modelling}

\subsubsection{Langmuir Isotherm}

Langmuir ${ }^{18}$ proposed an isotherm model that postulated monolayer adsorption of molecules onto a fixed number of active sites, with no lateral interaction between adsorbed molecules onto a morphologically homogeneous surface. Here, the adsorption sites are considered to be identical. The Langmuir equation is expressed as follows:

$$
q_{e}=\frac{Q_{o} K_{L} C_{e}}{1+K_{L} C_{e}}
$$

where $q_{e}$ is the amount of adsorbate adsorbed at equilibrium per unit mass of the adsorbent $\left(\mathrm{mg} \mathrm{g}^{-1}\right), C_{e}$ is the residual adsorbate concentration in the solution at equilibrium $\left(\mathrm{mg} \mathrm{L}^{-1}\right), Q_{0}$ is the maximum adsorption capacity $\left(\mathrm{mg} \mathrm{g}^{-1}\right)$ and $b$ is the Langmuir constant $\left(\mathrm{L} \mathrm{g}^{-1}\right)$. Equation 11 was linearized to three linear forms given in Table 4. Langmuir isotherm is also described in terms of the dimensionless parameter called the separation factor $\left(R_{L}\right)^{19}$ expressed as:

$$
R_{L}=\frac{1}{1+K_{L} C_{i}}
$$

\subsubsection{Freundlich Isotherm}

The Freundlich model ${ }^{20}$ postulates multilayer adsorption, with unequal dispersion of adsorption affinities onto the heterogeneous adsorbent surface without lateral interaction. The energetically favored adsorption sites are hypothesized to be occupied first followed by diminishing binding strength with increasing rates of site occupancy. The Freundlich equation is expressed as follows:

$$
q_{e}=K_{F} C_{e}^{1 n}
$$

The Freundlich equation is exponential thus assuming that the

Table 4 Linear isotherm model parameters.

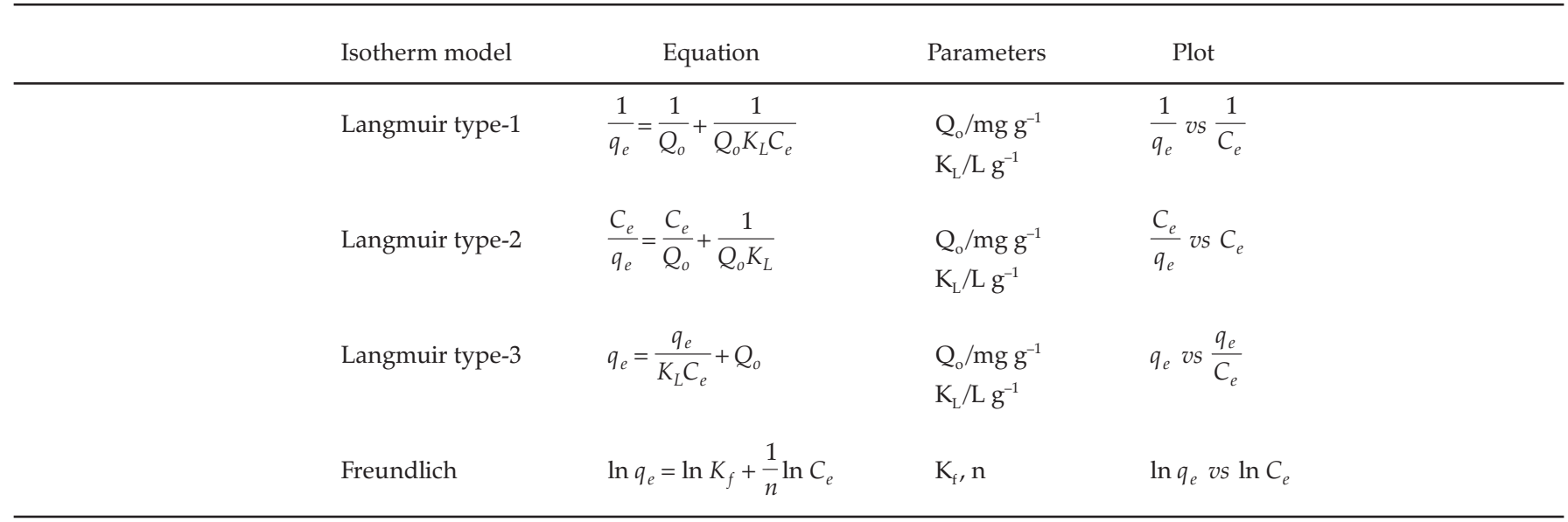

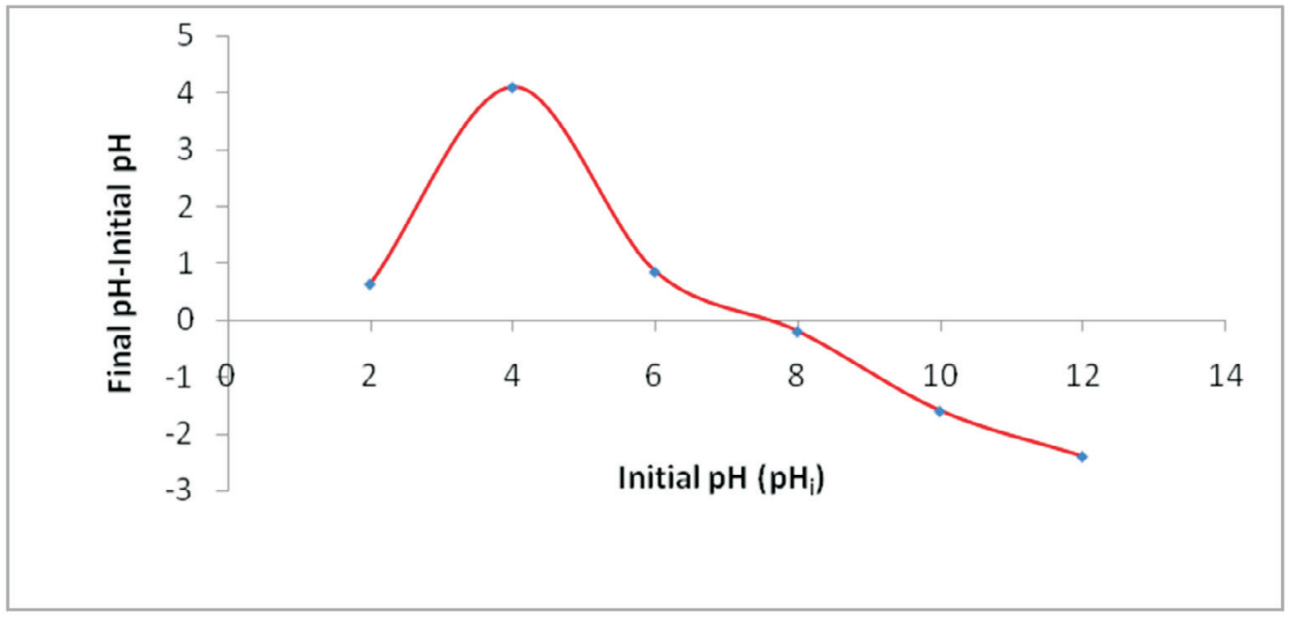

Figure 6 A plot of the point of zero charge $\left(\mathrm{pH}_{\mathrm{pzc}}\right)$ of natural zeolite. 


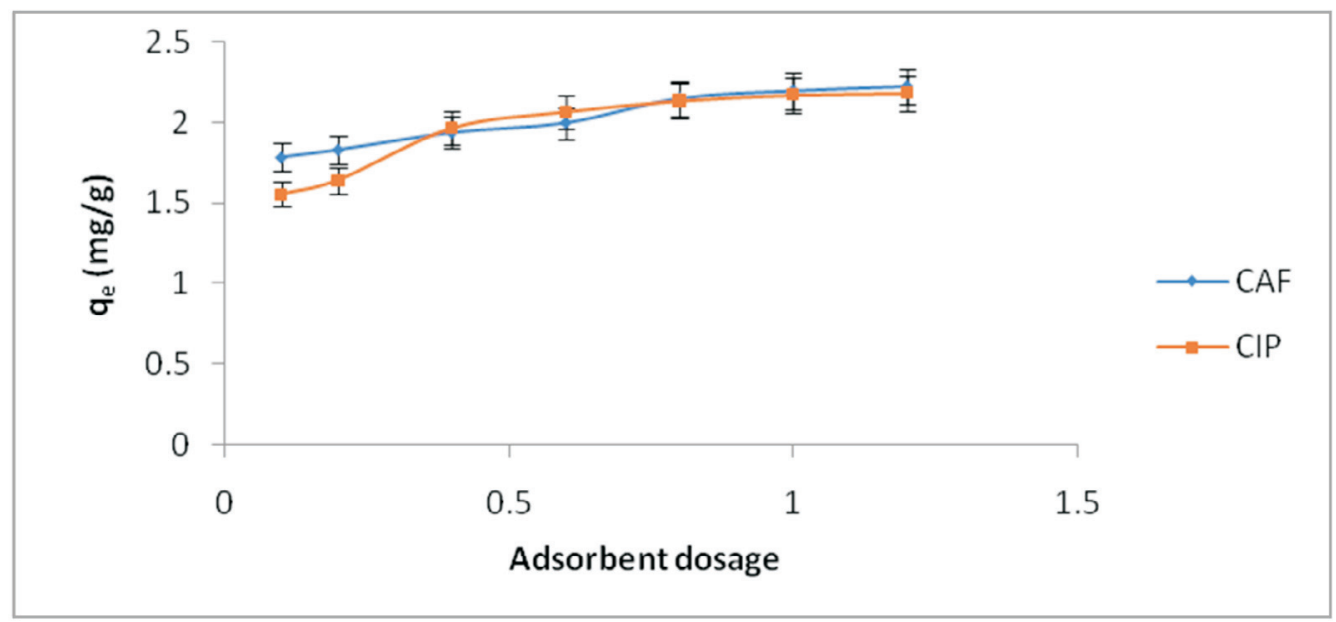

Figure 7 Variation of CAF and CIP adsorption as a function of adsorbent dosage (triplicate).

amount of adsorbate on the adsorbent surfaces increases with increase in solute concentration. According to Halsey, ${ }^{21}$ the Freundlich maximum adsorption capacity is given by the equation:

$$
K_{F}=\frac{q_{m}}{C_{i}^{1 n}}
$$

where $C_{i}$ is the initial solute concentration $\left(\mathrm{mg} \mathrm{L}^{-1}\right)$ and $q_{m}$ is the Freundlich maximum adsorption capacity $\left(\mathrm{mg} \mathrm{g}^{-1}\right)$. Linear form of Freundlich equation is shown in Table 4.

In this study, the applicability of two mathematical models to describe the adsorption data were examined, namely; Langmuir (three linear forms) and linear Freundlich model and the degree of conformity of the data to each model evaluated using the coefficient of determination $\left(\mathrm{R}^{2}\right)$. The calculated parameters are listed in Table 5.

All the Langmuir isotherm type equations had different $R^{2}$ values with Eadie-Hoffsiee linearization of Langmuir model (Type 3) posting the least coefficient of determination $\left(\mathrm{R}^{2}\right)$ despite its relatively wide usage among researchers. The other two equations, Lineweaver-Burk (type 1) and Hanes-Woolf (type 2) linearization of Langmuir model had varying coefficient of determination yielding dissimilarity in the calculated Langmuir parameters. This is attributed to the inherent error structures associated with transformation of non-linear functions to linear models. ${ }^{22,23}$ The coefficient of determination $\left(R^{2}\right)$ value therefore has a significant role in the choice of the best linear form of Langmuir isotherm. The theoretical Langmuir monolayer $\left(Q_{0}\right)$ maximum adsorption capacity parameter for CAF and CIP were comparable despite their wide variances in hydrophobicity. This suggests that hydrophobic interactions are not the driving forces of the adsorption mechanisms. Alternatively, the $Q_{o}$ values may be compared by nonlinear regression method owing to the aforementioned possible errors induced by linear regression.

According to Worch, ${ }^{24}$ the magnitude of the Freundlich parameter $n$ gives insights on the nature of the adsorption process to be either: unfavourable, $n>1$; linear $n=1$; favourable $n<1$; or irreversible $n=0$. In this work, the Freundlich constant for adsorption of both compounds onto the clinoptilolite was less than unity indicating favourable adsorption. This is consistently evidenced by the separation constant $\left(R_{L}\right)$ values which lie between 0 and 1 also descriptive of a favourable adsorption. ${ }^{19}$

The adsorption capacities of other adsorbents for CIP reported in previous studies were compared with the clinoptilolite evaluated in the present study (Table 6). It is evident that the natural
Table 5 Calculated adsorption isotherm parameters for CAF and CIP adsorption onto NZ-K (triplicate).

\begin{tabular}{lll}
\hline Isotherm model & \multicolumn{1}{c}{ CAF } & \multicolumn{1}{c}{ CIP } \\
\hline \multirow{2}{*}{ Freundlich } & $\mathrm{R}^{2}=0.990$ & $\mathrm{R}^{2}=0.994$ \\
& $\mathrm{n}=1.438$ & $\mathrm{n}=1.346$ \\
& $\mathrm{~K}_{\mathrm{f}}=1.099$ & $\mathrm{~K}_{\mathrm{f}}=0.865$ \\
Langmuir type-1 & $\mathrm{R}^{2}=0.999$ & $\mathrm{R}^{2}=0.996$ \\
& $\mathrm{Q}_{0}=5.479$ & $\mathrm{Q}_{0}=5.308$ \\
& $\mathrm{~K}_{\mathrm{L}}=0.260$ & $\mathrm{~K}_{\mathrm{L}}=0.199$ \\
& $\mathrm{R}_{\mathrm{L}}=0.435$ & $\mathrm{R}_{\mathrm{L}}=0.501$ \\
& $\mathrm{R}^{2}=0.995$ & $\mathrm{R}^{2}=0.968$ \\
& $\mathrm{Q}_{0}=5.362$ & $\mathrm{Q}_{0}=5.838$ \\
& $\mathrm{~K}_{\mathrm{L}}=0.268$ & $\mathrm{~K}_{\mathrm{L}}=0.174$ \\
& $\mathrm{R}^{2}=0.988$ & $\mathrm{R}^{2}=0.930$ \\
& $\mathrm{Q}_{0}=5.346$ & $\mathrm{Q}_{0}=5.528$ \\
& $\mathrm{~K}_{\mathrm{L}}=0.269$ & $\mathrm{~K}_{\mathrm{L}}=0.189$ \\
\hline
\end{tabular}

Table 6 Adsorption capacities of different adsorbents for CIP.

\begin{tabular}{lcc}
\hline Adsorbent & $\begin{array}{c}\text { Maximum adsorption } \\
\text { capacity } / \mathrm{mg} \mathrm{g}^{-1}\end{array}$ & Reference \\
\hline Kaolinite & 6.3 & 25 \\
Modified coal fly ash & 1.55 & 26 \\
Aluminous oxide & 13.6 & 27 \\
Kaolinite & 7.95 & 28 \\
Water hyacinth biochar & 2.7 & 29 \\
Zeolite (clinoptilolite) & 5.48 & This study \\
\hline
\end{tabular}

zeolite has comparable adsorption capacity and is therefore a low-cost alternative adsorbent.

\section{Conclusion}

Clinoptilolite is demonstrated to be a cheap and efficient resource material for $\mathrm{CAF}$ and $\mathrm{CIP}$ adsorption from water. The equilibrium adsorption data was best described by LineweaverBurk linearization of the Langmuir model (type-1) with a maximum adsorption density of $5.48 \mathrm{mg} \mathrm{g}^{-1}$ while the adsorption kinetics data fitted the pseudo-second-order (PSO) kinetic model. Linearization of Langmuir equation may potentially induce discrepancies in parameters calculated. However, in the present study $R^{2}$ values sufficiently depicted the degree of fitting to the linear forms of the Langmuir equation. CIP adsorption is 
strongly influenced by $\mathrm{pH}$ variation due to electrostatic interactions. The calculated thermodynamic functions indicated that the adsorption of CAF and CIP onto NZ-K is exothermic, spontaneous and physical in nature and not driven by hydrophobic interactions as testified by similar theoretical Langmuir maximum adsorption capacity values.

\section{Acknowledgement}

The authors are grateful to Association of African Universities (AAU) for providing funding for this work.

\section{${ }^{5}$ ORCID iD}

E.C. Ngeno: (D) orcid.org/0000-0002-9248-2320

\section{References}

1 K.O.K'oreje, K. Demeestere, P. De Wispelaere, L. Vergeynst, J. Dewulf and $\mathrm{H}$. Van Langenhove, From multi-residue screening to target analysis of pharmaceuticals in water: development of a new approach based on magnetic sector mass spectrometry and application in the Nairobi River basin, Kenya, Sci. Total Environ., 2012, 437: 153-164.

2 E. Ngumba, A. Gachanja and T. Tuhkanen, Occurrence of selected antibiotics and antiretroviral drugs in Nairobi river basin, Kenya, Sci. Total Environ., 2016, 539, 206-213.

3 J.L. Sotelo, G. Ovejero, A. Rodríguez, S. Álvarez, J. Galán and J. García, Competitive adsorption studies of caffeine and diclofenac aqueous solutions by activated carbon, Chem. Eng. J., 2014, 240, 443-453.

4 J.L. Sotelo, A. Rodríguez, S. Álvarez and J. García, Removal of caffeine and diclofenac on activated carbon in fixed bed column, Chem. Eng. Res. Design., 2012, 90(7), 967-97.

5 M. Galhetas, A.S. Mestre, M.L. Pinto, I. Gulyurtlu, H. Lopes and A.P. Carvalho, Chars from gasification of coal and pine activated with $\mathrm{K}_{2} \mathrm{CO}_{3}$ : acetaminophen and caffeine adsorption from aqueous solutions, J. Colloid Interface Sci., 2014, 433, 94-103.

6 V.O. Shikuku, R. Zanella, C.O. Kowenje, FF. Donato, N. Bandeira and O.D. Prestes, Single and competitive removal of sulfachloropyridazine and sulfadimethoxine onto natural kaolinite clay: kinetics, isotherms and thermodynamics, S. Afr. J. Chem., 2017, 70, 120-127.

7 M.B. Ahmed, J.L. Zhou, H.H. Ngo and W. Guo, Adsorptive removal of antibiotics from water and wastewater: progress and challenges, Sci. Total Environ., 2015, 532, 112-126.

8 V.O. Shikuku, F.F. Donato, C.O. Kowenje, R. Zanella and D.O. Prestes, A comparison of adsorption equilibrium, kinetics and thermodynamics of aqueous phase clomazone between faujasite $X$ and a natural zeolite from Kenya, S. Afr. J. Chem., 2015, 68, 245-252.

9 L. Damjanović, V. Raki, V. Rac, D. Stošić and A. Auroux, The investigation of phenol removal from aqueous solutions by zeolites as solid adsorbents, J. Hazard. Mater., 2010, 184, 477-484.

10 X. Li, C. Shuo, F. Xinfei, Q. Xie, T. Feng, Z. Yaobin and G. Jinsuo, Adsorption of ciprofloxacin, bisphenol and 2-chlorophenol on electrospun carbon nanofibers: in comparison with powder activated carbon, J. Colloid Interface Sci., 2015, 447, 120-127.
$11 \mathrm{H}$. Hosseinzadeh and S. Mohammadi, Quince seed mucilage magnetic nanocomposites as novel bioadsorbents for efficient removal of cationic dyes from aqueous solutions, Carbohydr. Polymers, 2015, 134, 213-221.

12 Omri, W. Ahmed and B. Mourad, Adsorption of bentazon on activated carbon prepared from Lawsoniainermis wood: equilibrium, kinetic and thermodynamic studies, Arab. J. Chem., 2012, http://dx.doi.org/10.1016/j.arabjc.2012.04.047

13 Y.S. Ho and G. McKay, Sorption of dye from aqueous solution by peat, Chem. Eng. J., 1998, 70, 115-124.

14 Y.S. Ho, Review of second-order models for adsorption systems, J. Hazard. Mater., 2006, 136, 681-689.

15 W.J. Weber Jr. and J.C. Morris, Kinetics of adsorption on carbon from solutions, J. Sanitary Eng. Div. ASCE, 1963, 89(2), 31-60.

16 W. Plazinski, W. Rudzinski and A. Plazinska, Theoretical models of sorption kinetics including a surface reaction mechanism: a review, Adv. Colloid Interface Sci., 2009, 1-2, 2-13.

17 H.M. Baker and R. Ghanem, Evaluation of treated natural zeolite for the removal of O-chlorophenol from aqueous solution, Desalination, $2009,249,1265-1272$.

18 I. Langmuir, The constitution and fundamental properties of solids and liquids, J. Am. Chem. Soc., 1916, 38, 2221-2295.

19 K.R. Hall, L.C. Eagleton, A. Acrivos and T. Vermeulen, Pore- and solid-diffusion kinetics in fixed-bed adsorption under constant pattern conditions, Ind. Eng. Chem. Fundam., 1966, 5, 212-223.

20 H.M.F. Freundlich, Über die adsorption in lösungen, Z. Phys. Chem., $1906,57,385-470$.

21 G.D. Halsey, The role of surface heterogeneity, Adv. Catal., 1952, 4 , 259-269.

22 Y.S. Ho and T.H. Chiang, Y.M. Hsueh, Removal of basic dye from aqueous solution using tree fern as a biosorbent, Process Biochem., 2005, 40(1), $119-124$.

23 V.O. Shikuku., C.O. Kowenje and F. Kengara, Errors in parameters estimation using linearized adsorption isotherms: sulfadimethoxine adsorption onto kaolinite clay, Chem. Sci. Inter. J., 2018, 23 (4), 1-6.

24 E. Worch, Adsorption Technology in Water Treatment: Fundamentals, Processes, and Modeling, Walter de Gruyter, 2012.

25 Z.H. Li, H.L. Hong, L.B. Liao, C.J. Ackley, L.A. Schulz, R.A. MacDonald, et al., A mechanistic study of ciprofloxacin removal by kaolinite, Colloids Surf. B: Biointerfaces, 2011, 88(1), 339-344.

26 C.L. Zhang, G.L. Qiao, F. Zhao and Y. Wang, Thermodynamic and kinetic parameters of ciprofloxacin adsorption onto modified coal fly ash from aqueous solution, J. Mol. Liquids, 2011, 163(1), 53-56.

27 C. Gu and K.G. Karthikeyan, Sorption of the antimicrobial ciprofloxacin to aluminum and iron hydrous oxides, Environ. Sci. Technol., 2005, 39(23), 9166-9173.

28 A.A. Mackay and D.E. Seremet, Probe compounds to quantify cation exchange and complexation interactions of ciprofloxacin with soils, Environ. Sci. Technol., 2008, 42(22), 8270-8276.

29 E. Ng'eno, F. Orata, D.B. Lilechi, V.O. Shikuku and S. Kimosop, Adsorption of caffeine and ciprofloxacin onto pyrolytically derived water hyacinth biochar: isothermal, kinetics and thermodynamics, J. Chem. Chem. Eng., 2016, 10, 185-194. 